\title{
A Proposed Training Program to Mix Physical Fitness with Skillful Performance for Younger Basketball Players
}

\author{
Mohamed Abdul-Hamid Belal*
}

The research aims to develop physical fitness and skillful performances of young basketball players (mini basketball players) in a training environment suited to their needs and abilities through the identification of the effect of the proposed Training Program to mix the physical with the skillful training on the development of a number of special physical abilities and the improvement of certain skillful performances in younger basketball players (mini basketball players).

The researcher used the experimental method, with one group, being suitable to this type of study, applying the program to the research group using a mix of skillful and physical training exercises simultaneously. The basic experience was carried out on basketball players younger than 12 years-old at Semouha Sports Club in Alexandria $(N=20)$. and included the content of the program on a training group in terms of the difficulty of performance, which is aimed to capacity-development for this special physical age (Flexibility-SpeedAgility- Coordination - explosive strength) as well as to improve the level of skills performance (Ball handling-Dribbling- Passing - Shooting - Rebounding)

Within the results that could be reached from data analysis obtained will enable the researcher to draw the following:

- Suggested Training Program, which is a mix of physical \& skills preparation and led to the development of the Physical fitness (Speed -Agility- Flexibility- Accuracy - Coordination - Explosive Strength) to young basketball players less than 12 years.

- Suggested Training Program, which is a mix of physical \& skills preparation and led to the improvement of the performances skills (Lay-up shot - Jump Shot-Rebounding - Passing - Dribbling) for young basketball players less than 12 years.

\section{Introduction:}

$\mathbf{T}$ he Basketball game is one of the most games in the world to raise collective, enjoyable and suspense for each of the players and spectators, the diversity skills and different ways of continuing to play and amendments to the law have contributed to increase speed of the play, beside, special technical skills which not exist in many other collective games.

In view of enjoyed the Basketball by many and different skills, the diversity of methods of competition to suit the different needs of its official international and local championships, adults and young people of various ages, all this brought to a distinctive feature of the Basketballmade it in a need to develop and reform

*Assistant Professor, Sports Games Training Department, , The Faculty of Physical Education, Abu Qir, Alexandria University, Egypt. continues in training methods by those responsible for it in order to increase the fun and exciting players and spectators and practitioners.

Mini-basketball as defined by the law of the International Federation of basketball FIBA (2005) is a game of basketball for adults, but modified commensurate with the ability of children and the Basketball game play with big ball and aiming for shooting are high, but in the mini-Basketball has been minimized the downsizing of the ball, and requires the participation of all the players in the match for a period of at least one, and the Basketball for adults containing a lot of substantive law, these laws have been reduced by the least possible in the mini- Basketball.

Shaban Ibrahim (2003) defined it as a game based on the same grounds as the real Basketball game but somewhat modified to be 
enabled to play by children, boys and girls under the age of 12 .

The researcher sees that the mini- Basketball seek to provide children to the world of the Basketball in an atmosphere by love and attention and suspense, the mini-basketball is the first step for children to process the exercise to play Basketball, to provide an excellent means of children to play sport through physical education programs regulated during the first years of practice.

The objectives of the philosophy of the stage of mini- Basketball as articulated by Martin Lee (1998) : educate children the basic skills of basketball in an environment suited to their needs and abilities, increasing opportunities for children to participate in playing at various levels and capacities, the provision of opportunities for creativity, social interaction, the creation of the spirit of the Group, the implantation of the principles of fair play and to take responsibility and show that sport for fun.

The researcher emphasizes that the stage of the Basketball for young people (Mini Basket) for age (9-12) is the best to learn basic skills of the game, AfafAbd al-Karim (1993) confirms that the nature of this stage is considered one of the best stages in learning, due to the biological and the psychological characteristics for this age.

It is important that when children graduates in this age to has a degree of basic skills that help him on the performance of the plans, which will be earning in the next stages, and therefore must does the performance of the skills of:

- Footwork

- Dribbling

- Passing

- Shooting

- Defense

- Defense Movements

- 1/1 games- simplified

- 2/2 games- simplified

- 3/3 games- simplified

Shaban Ibrahim (2003) mentioned that the training of the Basketball for young people must be done in several stages, the first of which is learning basic skills, in which the offensive and defensive player learn how to deal with himself through a series of exercises, which is dubbed "the movement exercises". Followed by, strict training move, which aims to learn how the player control himself with the ball, and then learn how to control himself with the ball and with the place, then comes the second stage, which is helping the player to acquire the performance of simple basic plans such as the awareness of the colleague and the awareness of the opponent and a sense of time and adaptation to play under the circumstances of jamming factors

Bastaweesy Ahmed (1996) adds that the children of the age of 9-12 is characterized by slow development in the performance of the skills that require the use of eyes and parties such as catch, kicked, hit the ball, throwing.... etc. therefore, need such skills to the exercise a lot until the child could be able to perform accurately, considers this period of transition from the stage of refining capacity dynamic skills to the stage of the establishment of transitional movement, games, and sport skills, The first years of this period is characterized by the focus of the Child about himself and the lack of good interaction in playing with large groups, while the child could interact in playing with small groups.

Ali Fahmi El-Bik (1992) mentions that it is necessary to focus on physical character, according to each age until there is the biggest development of these physical characteristics, the age of 9-11 years is important to focus on the Movement speed, Agility, reaction coordination and performance flexibility.

Despite the clarity of the objectives of the philosophy of mini-basketball as articulated by Martin Lee (1998), and also referred to American Sport Education Program (2001), for fun and suspense practice rather than competition, but through the researcher's work in the field of the mini Basketball training for several seasons, and taking place as a head of the mini- basketball committee in Alexandria and member of the Supreme Committee of mini-basketball in the Egyptian Basketball Federation, it was noted that the coaches focus on wining in the matches and dealing with young people at this age as advanced players in 
terms of giving training or the form of the exercises, which lead to the unwillingness to continue, as well as lead to weariness in performance during training and lost the suspense.

The importance of research, is to give the suspense and excitement to the Child at this age through designing training exercise that serve the physical \& skill side, where the player has the ball since the beginning of the training till the end to develop the physical fitness for this age, as well as improving performance which is giving the excitement and stimulation of the game and could lead to improved physical abilities of this age, the researcher supposed that this training program, which contains a group of exercises may lead to the development of some special physical abilities and improve the level of performance for mini- basketball players less than 12 years-old.

\section{Aim of the research:}

The development of the physical abilities, performances for young age basketball players in a training environment suited to their needs and abilities through identified:

1. The impact of the proposed training program to mix between physical and skills training on the development of some of the physical abilities to young age basketball players.

2. The impact of the proposed training program to mix between physical and skills training on the improvement of some of the physical abilities to young age basketball players.

\section{Previous Studies:}

The study results of Maria Canadas et al (2009) indicate the relationship between educational variables in Mini- Basketball training, during analysis of the training process of the mini Basketball used the descriptive approach, for studying 452 training position for mini basketball which resulted that there is interest from the trainers about the offense skills more than the defense skills particularly the shooting skills.
The study results of Pinar, $\mathrm{M}^{\mathrm{a}}$ Isabe (2009) studied the practice of basketball for young age through reducing the area of competition, study the impact of the stadium and reduce the number of players to 3 players, used the Experimental curriculum on 47 young age basketball playerswhich resulted that the individual involvement was better in the case of small-amendments in the competition.

The Study of AmerSaadAmer (2008) showed the impact of proposed amendments in the Law of the Basketball for young age players on the effectiveness of the offensive action collective. The purpose of study was to identify more appropriate variables offensive action of the mini-basketball. Use the descriptive curriculum. The study sample included two sets of groups of 8 basketball teams. Results of increase the effectiveness of the variables collective offensive action for team's players were born on 95, which have been applied by the amendments of the law more than those who born on 94 .

The study of Sanaa Abbas Ibrahim (2006) mentioned the development of the activist performance for basic skills used in dynamic training for basketball players age (9-12) years, to identify the impact of the proposed training program for the development of dynamic performances for the basketball players (9-12) years, used the descriptive and empirical approach with two groups. The study sample included 25 players less than 12 years. The result was that there is existence of statistical differences of the Group, which has been applied by the training program.

The Study of Omar Shaker\&Sanaa Abbas (1999) studied the amendment to the sizes of the basketball court for young age players (in the mini basketball) in accordance with the rules of the Specialists in ergonomicsand human factors and its impact on the physiological performance for some of the body organs. The study included a proposal for basketball playground for young age players by applying the rules and ways of Specialists in ergonomicsand human factors.

To identify the physiological effects of the proposed court on young players, and average of achievement in the stadium with sizes proposed. The curriculum used descriptive (the way the surveyors) selection of sample had been 
intentional (200) mini basket players and (100) advance level players in general league. The result was that the proposed court contributed in the improvement of the performance level and biochemical performance.

\section{Research Statement:}

Throughout the access to theoretical studies and analyses the results of previous studies and researches, the researcher could be drafting the following assumptions:

1. Suggested training program is leading to the development of some of the physical abilities for young age basketball players.

2. Suggested training program is helping to improve the level of some performances skills for young age basketball players

Table (1) The Arithmetic Mean, the Standard Deviation and the value of Coefficient of Skewness and Coefficient of Kurtosis in the main measurements for the research sample

\begin{tabular}{|c|c|c|c|c|c|c|c|}
\hline $\mathbf{N}$ & Variables & $\begin{array}{c}\text { Arithmetic } \\
\text { Mean }\end{array}$ & $\begin{array}{l}\text { Standard } \\
\text { Deviation } \\
\end{array}$ & $\begin{array}{c}\text { Minimum } \\
\text { value }\end{array}$ & $\begin{array}{c}\text { Maximum } \\
\text { value }\end{array}$ & Kurtosis & Skewness \\
\hline 1 & Age (y) & $1 \cdot . \varepsilon$ & $\cdot r \cdot$ & $9.7 \leqslant$ & $1 \cdot{ }^{\prime}$ & $.0 V_{-}$ &.$V \tau_{-}$ \\
\hline 2 & Height (m) & $1 . \leqslant Y$ & $\because 0$ & $1 . r \varepsilon$ & 1.01 & $\cdot 1 \cdot-$ & $1.1 \mathrm{~V}_{-}$ \\
\hline 3 & Weight (kg) & rq.V & $1 \cdot . \leqslant r$ & re & 70 & $1 . r \wedge$ & 1.1 \\
\hline 4 & Age Training (month) & $1 \leq .10$ & $0.9 V$ & $\wedge$ & $r \leq$ & 1.1 & $.71-$ \\
\hline
\end{tabular}

It is clear from the Table (1), the transactions of Coefficient of Skewness basic variables of a sample research near zero and transactions of Coefficient of Kurtosis confined between ( \pm 3$)$, which indicates moderation values and harmony between members of the research sample.

\section{The Time-Frame Area:}

- The pre- evaluation measurements conducted on 2 days 1-2/07/2010

- The research experiment measurement conducted from 4/7/1010 till 26/9/2010

- The post evaluation measurements conducted on 2 days 28-29/9/2010

The Geographical Area:

The experience of basic research conducted in the stadium of the legal Basketball court at Somouha sports Club for young basketball players.

\section{The Research Tools:}

1. Legal Basketballs for Young age players (mini4. The Agility measurements (running zig-zag) basketball)
2. Stop Watch

3. Measurements tape $(\mathrm{cm})$

4. Scale

5. Cones

6. Medicine Basketballs with different weights

\section{Tests and Measurements}

The Fitness tests: (Mohamed sobhiHassanein 2004)

1. The Flexibility Measurements (bend the upper body down) $(\mathrm{cm})$

2. The Coordination measurements (the numerical circles) ( sec.)

3. The Speed measurements ( $20 \mathrm{~m}$. Running) ( sec.)

(sec.) 
5. The Explosive strength for legs ( Vertical jump) implemented during the period of (cm.) preparation.

6. The Explosive strength for arms (pushing a $1 \mathrm{~kg} 3$. Determine the number of the weekly training medicine ball as far as he can from stability (m.) units by 3 units weekly.

Skills Tests: (Mohamed AbdelDaym, Mohamed SobhiHassanein 1999)

1. Speed and Accuracy of passing test (points)

2. Speed of dribbling with shooting test (second)

3. Agility of dribbling test (Second)

4. Speed and Accuracy of jump shooting test (points)

5. Speed and Accuracy of lay-up shooting test (points)

6. Rebounding test ( points

\section{The main experiments research:}

\section{First: The pre-evaluation measurement:}

The researcher conducted the pre-evaluation measurement on the research sample on 1$2 / 7 / 2010$, by confirming some of the variables which affect the impact of the experimental variable in order to ensure the variable sincere (mixed between physical and skills exercises) on the changing of (some of the physical abilities, performances for young basketball players), using a set of measurements and tests that have already been codified in previous studies and research has proved its sincerity and constancy and objectivity as well as its possible relevance of the research sample.

\section{Second: The main experiments research:}

Through previous studies and reference scientific researches related to the theme, enabled the researcher to manage to reach results represent the basic steps:

1. Determine the program period of the Group for 12 weeks.

2. Determine the period of time to study from $4 / 7 / 2010$ to $26 / 9 / 2010$, has been
4. The number of training units is 36 units.

5. Determine the duration of each training unit by 120 minutes.

6. Train the experimental group through different exercises to mix between the physical and skills performance.

7. The fundamentals of the training program.

- The selection of the content of the training program chosen based on the analysis of training programs and studies of the stage of the young Basketball players on either the physical or skills side, which referred to previous studies, researches, scientific publications and Internet sites.

- The content of the program contains a group of exercises in terms of the severity of the difficulty of performance, which is aimed to develop special physical skills ( flexibility. speed - agility- coordination - explosive strength) as well as to improve the level of performance skills ( ball handling dribbling- passing - shooting - rebounding) has developed, the researcher has put the selection of the following conditions:

- Control the ball from the beginning to the end of the exercise.

- Doing all the exercises while controlling the ball.

- Doing any exercise that serve the Physical and skills performance together.

- Gradually in the exercises strength.

- Gradually in the exercises time.

- To be similar with the same performance in the matches

- The training program had been distributed for physical fitness and performances skills for 12 weeks as shown in Table (2) 
Table (2) shows the duration period of the

Physical fitness and performance skills through the Proposed Training Program

\begin{tabular}{|c|c|c|c|c|}
\hline Week & Physical Training & + & Skill Training & $\begin{array}{c}\text { Time per } \\
\text { Week } \\
\text { (Minutes) }\end{array}$ \\
\hline \multirow{7}{*}{$\begin{array}{c}\text { First } \\
\text { A total of } \\
360 \\
\text { minutes } \\
\text { weekly }\end{array}$} & Warm Up - Stretching \& Flexibility & + & Ball handling & $\leqslant 0$ \\
\hline & $\begin{array}{c}\text { Coordination }- \text { Explosive Strength for } \\
\text { Legs }\end{array}$ & + & Footwork & $\leqslant 0$ \\
\hline & $\begin{array}{c}\text { Accuracy - Explosive Strength for } \\
\text { Arms } \\
\end{array}$ & + & Chest pass & 7. \\
\hline & Speed & + & Dribbling of stability in a straight line & 7. \\
\hline & Accuracy & + & Shooting of stability & ¿0 \\
\hline & Accuracy - Speed & + & Lay up shot from Dribbling & 7. \\
\hline & Integration & + & Mini Games & $\leq 0$ \\
\hline \multirow{7}{*}{$\begin{array}{l}\text { Second } \\
\text { A total of } \\
360 \\
\text { minutes } \\
\text { weekly }\end{array}$} & Warm Up - Stretching \& Flexibility & + & Ball handling & $\leq 0$ \\
\hline & $\begin{array}{c}\text { coordination }- \text { Explosive Strength for } \\
\text { Legs }\end{array}$ & + & Footwork & $\leqslant 0$ \\
\hline & $\begin{array}{c}\text { Accuracy - Explosive Strength for } \\
\text { Arms }\end{array}$ & + & Bounce Pass & ฯ. \\
\hline & Speed - Agility & + & Change-Of-Pace Dribble & 纟o \\
\hline & Accuracy - Explosive Strength & + & Jump Shot & 7. \\
\hline & Accuracy - Speed - Agility & + & Lay up shot from Dribbling \& Pass & 7. \\
\hline & Integration & + & Mini Games & $\leqslant 0$ \\
\hline \multirow{8}{*}{$\begin{array}{l}\text { The third } \\
\text { A total of } \\
360 \\
\text { minutes } \\
\text { weekly }\end{array}$} & Warm Up - Stretching \& Flexibility & + & Ball handling & $\leq 0$ \\
\hline & $\begin{array}{c}\text { coordination -Explosive Strength for } \\
\text { Legs }\end{array}$ & + & Footwork & $\leq 0$ \\
\hline & $\begin{array}{c}\text { Accuracy - Explosive Strength for } \\
\text { Arms } \\
\end{array}$ & + & Overhead Pass & «o \\
\hline & Speed - Agility & + & Behind-the-Back Dribble & «0 \\
\hline & Accuracy - Explosive Strength & + & Jump Shot & $\leq 0$ \\
\hline & Accuracy - Speed - Agility & + & Lay up shot from Dribbling \& Pass & «o \\
\hline & Explosive Strength for Legs & + & Defensive movements & £० \\
\hline & Integration & + & Mini Games & $\leqslant 0$ \\
\hline \multirow{9}{*}{$\begin{array}{l}\text { The fourth } \\
\text { A total of } \\
360 \\
\text { minutes } \\
\text { weekly }\end{array}$} & Warm Up - Stretching \& Flexibility & + & Ball handling & $\leqslant 0$ \\
\hline & $\begin{array}{c}\text { coordination - Explosive Strength for } \\
\text { Legs }\end{array}$ & + & Footwork & r. \\
\hline & $\begin{array}{c}\text { Accuracy - Explosive Strength for } \\
\text { Arms } \\
\end{array}$ & + & Side Pass - Behind-the-Back Pass & $\leq 0$ \\
\hline & Speed - Agility & + & Through Legs Dribble & $\leq 0$ \\
\hline & Accuracy - Speed & + & Jump Shot from Dribbling & $\leqslant 0$ \\
\hline & $\begin{array}{c}\text { Accuracy - Speed - coordination - } \\
\text { Agility } \\
\end{array}$ & + & Lay up shot from Dribbling \& Pass & $\leqslant 0$ \\
\hline & Speed - Explosive Strength for Legs & + & Defensive movements & $r$. \\
\hline & Integration & + & $1 / 1$ & $r$. \\
\hline & Integration & + & Mini Games & $\leqslant 0$ \\
\hline The Fifth & Warm Up - Stretching \& Flexibility - & + & Ball handling & $\leqslant 0$ \\
\hline
\end{tabular}




\begin{tabular}{|c|c|c|c|c|}
\hline \multirow{7}{*}{$\begin{array}{c}\text { A total of } \\
360 \\
\text { minutes } \\
\text { weekly }\end{array}$} & \multicolumn{3}{|l|}{ coordination } & \multirow[b]{2}{*}{7.} \\
\hline & $\begin{array}{c}\text { Accuracy - Explosive Strength for } \\
\text { Arms }\end{array}$ & + & Baseball Pass & \\
\hline & Speed - Agility & + & Sweep Dribble & $\leq 0$ \\
\hline & $\begin{array}{l}\text { Accuracy - coordination -Speed - } \\
\text { Explosive Strength for Legs }\end{array}$ & + & Complex Exercise \& Jump shot & 纟o \\
\hline & Accuracy - Speed - Agility & + & Complex Exercise \& Lay up & 7. \\
\hline & Integration & + & $1 / 1$ & $\leqslant 0$ \\
\hline & Integration & + & Mini Games & 7. \\
\hline \multirow{8}{*}{$\begin{array}{l}\text { The sixth } \\
\text { A total of } \\
360 \\
\text { minutes } \\
\text { weekly }\end{array}$} & $\begin{array}{c}\text { Warm Up - Stretching \& Flexibility - } \\
\text { coordination }\end{array}$ & + & Ball handling & $\leqslant 0$ \\
\hline & $\begin{array}{c}\text { Accuracy - Explosive Strength for } \\
\text { Arms } \\
\end{array}$ & + & Passing & $\leqslant 0$ \\
\hline & Speed - Agility & + & Spin Dribble & $\leqslant 0$ \\
\hline & $\begin{array}{c}\text { Accuracy - coordination - Speed - } \\
\text { Explosive Strength for Legs }\end{array}$ & + & Complex Exercise \& Jump shot & $\leqslant 0$ \\
\hline & Accuracy - Speed - Agility & + & Complex Exercise \& Lay up & «o \\
\hline & Integration & + & Cutting $2 / 2$ & «o \\
\hline & Integration & + & Mini Games & $\leqslant 0$ \\
\hline & Integration & + & Games & «o \\
\hline \multirow{7}{*}{$\begin{array}{c}\text { The } \\
\text { seventh } \\
\text { A total of } \\
360 \\
\text { minutes } \\
\text { weekly }\end{array}$} & $\begin{array}{c}\text { Warm Up - Stretching \& Flexibility - } \\
\text { coordination }\end{array}$ & + & Ball handling & $\leqslant 0$ \\
\hline & Speed - Agility & + & Crossover Dribble & «o \\
\hline & $\begin{array}{c}\text { Accuracy - coordination -Speed - } \\
\text { Agility - Accuracy } \\
\end{array}$ & + & Complex Exercise & $\leqslant 0$ \\
\hline & coordination -Explosive Strength & + & Rebounding & 7. \\
\hline & Integration & + & Cutting $2 / 2$ & 7. \\
\hline & Integration & + & Mini Games & $\leqslant 0$ \\
\hline & Integration & + & Games & 7. \\
\hline \multirow{5}{*}{$\begin{array}{l}\text { The eighth } \\
\text { A total of } \\
360 \\
\text { minutes } \\
\text { weekly }\end{array}$} & $\begin{array}{c}\text { Warm Up - Stretching \& Flexibility - } \\
\text { coordination }\end{array}$ & + & Ball handling & «o \\
\hline & $\begin{array}{c}\text { Accuracy - Speed - Explosive Strength } \\
\text {-Agility }\end{array}$ & + & Complex Exercise & ir. \\
\hline & Integration & + & Screen 2 / 2 & 7. \\
\hline & Integration & + & Mini Games & $\leqslant 0$ \\
\hline & Integration & + & Games & 9. \\
\hline \multirow{5}{*}{$\begin{array}{l}\text { The ninth } \\
\text { A total of } \\
360 \\
\text { minutes } \\
\text { weekly }\end{array}$} & $\begin{array}{c}\text { Warm Up - Stretching \& Flexibility - } \\
\text { coordination }\end{array}$ & + & Ball handling & $\leqslant 0$ \\
\hline & $\begin{array}{c}\text { Accuracy - Speed - Explosive Strength } \\
\text {-Agility }\end{array}$ & + & Complex Exercise & ir. \\
\hline & Integration & + & Screen $2 / 2$ & 7. \\
\hline & Integration & + & Mini Games & $\leqslant 0$ \\
\hline & Integration & + & Games & 9. \\
\hline \multirow{3}{*}{$\begin{array}{l}\text { Tenth } \\
\text { A total of } \\
360 \\
\text { minutes }\end{array}$} & $\begin{array}{c}\text { Warm Up - Stretching \& Flexibility - } \\
\text { coordination }\end{array}$ & + & Ball handling & «o \\
\hline & $\begin{array}{c}\text { Accuracy - Speed - Explosive Strength } \\
\text {-Agility } \\
\end{array}$ & + & Complex Exercise & ir. \\
\hline & Integration & + & Cutting 3 / 3 & 7. \\
\hline
\end{tabular}




\begin{tabular}{|c|c|c|c|c|}
\hline weekly & Integration & + & Games & ס ק ו \\
\hline \multirow{4}{*}{$\begin{array}{l}\text { Eleventh } \\
\text { A total of } \\
360 \\
\text { minutes } \\
\text { weekly }\end{array}$} & $\begin{array}{c}\text { Warm Up - Stretching \& Flexibility - } \\
\text { coordination }\end{array}$ & + & Ball handling & $\leq 0$ \\
\hline & $\begin{array}{c}\text { Accuracy - Speed - Explosive Strength } \\
\text {-Agility }\end{array}$ & + & Complex Exercise & Ir. \\
\hline & Integration & + & Screen 3 / 3 & 7. \\
\hline & Integration & + & Games & 1ro \\
\hline \multirow{3}{*}{$\begin{array}{l}\text { Twelfth } \\
\text { A total of } \\
360 \\
\text { minutes } \\
\text { weekly }\end{array}$} & $\begin{array}{c}\text { Warm Up - Stretching \& Flexibility - } \\
\text { coordination }\end{array}$ & + & Ball handling & «o \\
\hline & $\begin{array}{c}\text { Accuracy - Speed - Explosive Strength } \\
\text {-Agility }\end{array}$ & + & Complex Exercise & 1 \\
\hline & Integration & + & Games & 11. \\
\hline
\end{tabular}

- The definition of integration is that the training serve all the physical fitness for certain age.

- The exercises characterized by speed and Accuracy.

- Moving from week to another leads to increase of the exercises to serve more than one skill.

- The Duration of the performance ranged between (5-10 second) for each training according to the goal of the training.
- The Duration for the rest period between the training ranged between (1-2 second), according to the goal of the training.

\section{Third: Post evaluates measurements:}

The researcher conducted the post evaluate tests and measurements on 28-29 / 9 / 2010, which had been prepared for the statistical analysis.

\section{Discussion:}

First: Discussion the results of the Body Measurements:

Table (3) The Arithmetic Mean, the Standard Deviation, Percentage of improvement and T-test between the pre and in between Fitness tests in the main measurements for the research sample

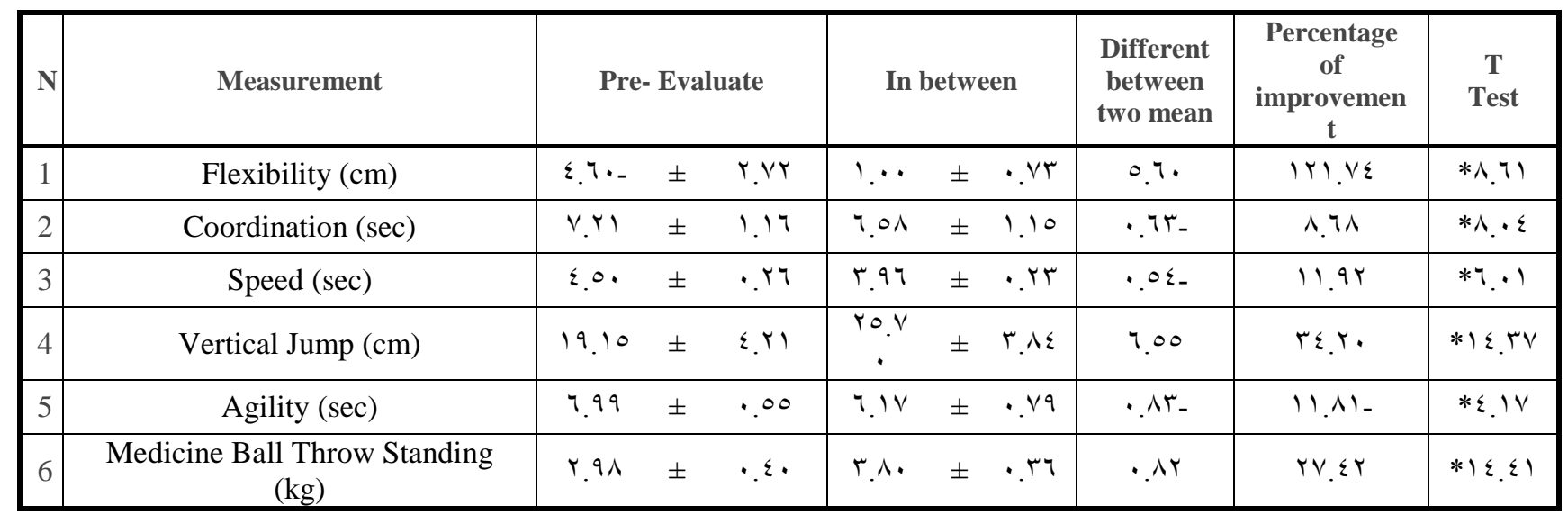

T-test $=2.93$ at 0.05 
Table (4) The Arithmetic Mean, the Standard Deviation, Percentage of improvement and T-test between the pre and post evaluate Fitness tests in the main measurements for the research sample

\begin{tabular}{|c|c|c|c|c|c|c|c|c|}
\hline $\mathbf{N}$ & Measurement & \multicolumn{2}{|c|}{ Pre- Evaluate } & \multicolumn{2}{|c|}{ Post Evaluate } & $\begin{array}{l}\text { Different } \\
\text { between } \\
\text { two mean }\end{array}$ & $\begin{array}{c}\text { Percentage } \\
\text { of } \\
\text { improvemen } \\
t \\
\end{array}$ & $\begin{array}{c}\text { T } \\
\text { Test }\end{array}$ \\
\hline 1 & Flexibility (cm) & $\varepsilon .7 \cdot-\quad \pm$ & r.Vt & r.o. & \pm .79 & A. $1 \cdot$ & $1 \vee 7.9$ & $* 1 \leq .7 V$ \\
\hline 2 & Coordination (sec) & V.YI \pm & 1.17 & 0.90 & $\pm \cdot .9 r$ & $1 . r_{-}$ & $1 V .01$ & $* 1$ r.90 \\
\hline 3 & Speed (sec) & $\varepsilon .0 . \quad \pm$ &.$Y T$ & 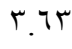 & \pm .19 & $\cdot \wedge V_{-}$ & $19.1 \varepsilon$ & *11.r \\
\hline 4 & Vertical Jump (cm) & $19.10 \pm$ & $\varepsilon . Y_{1}$ & r. 9 & \pm r.ls & 11.10 & רות & $* 19 . \mu$ \\
\hline 5 & Agility (sec) & $7.99 \quad \pm$ & .00 & 0.09 & $\pm \cdot r$ o & $1 . \varepsilon \cdot-$ & $r \cdot \cdot 1$ & שוץ \\
\hline 6 & Medicine Ball Throw Standing (kg) & r.q^ \pm & $\because \varepsilon$ & $\varepsilon .11$ & $\pm \cdot r$ ro & 1.11 & rV.qV & * $1 \leq . \mathrm{V}$ \\
\hline
\end{tabular}

T-test $=2.93$ at 0.05

Table(3) shows the differences with significance at the level of statistical measurement 0.05 between pre-evaluate \& post evaluate in physical measurements to improve measurement at rates ranging between $(8.68 \%$ : $121.74 \%$ ), is also apparent from table (4) the differences of statistical at the level of 0.05 between pre-evaluate \& post evaluate measurements in physical measurements at rates ranging between $(20.01 \%$ : 176.09\%).

This difference is due to the improvement in all physical measurements for the age less than 12 years (the stage of the young Basketball players) to the proposed training program, which is a mix of physical and skills preparation, where all the training exercises characterized by speed in the program performance, which has helped to develop speed and agility where that exercise was quickly lead transitional high such as in a straight line exercise, dribbling, and passing by movement.

In addition to that, the use of the ball during the exercises, helped to develop the coordination in the proposed training program, such as dribbling with quickly high transition or passing with high speed, and flexibility exercises such as holding 2 balls at the same time.

During the continues in the training program helped to give training warm-up exercises, flexibility exercises, which lead to an improvement in the flexibility in both pre-and post evaluate measurements.

Explosive power has improved for arms and legs as a result of the nature of performance in the training program, such as shooting exercise and dribbling with high speed or dribbling with jump or run as well as passing using legal basketballs or medicine balls which has helped to the development of the explosive power for arms.

The researcher sees that the nature of the skills performance in the Basketball will help to the develop the physical fitness and skills of the player when he runs fast zig-zag, which lead to the development of speed and agility as well as to improve the dribbling skill, when the player repeats the follow up training to get the ball that will lead to develop the explosive strength for legs and the harmony of coordination follow-up, when passing the ball continuously using legal balls will lead to the development of the explosive strength for arms as well as the passing skill, the training for controlling the ball helped to develop the harmony of coordination, as well as the development of the sense of the ball, flexibility exercise in the beginning of the training with the ball helps the development of the flexibility, coordination and a sense of the ball, This confirms the results of Efstratios Vamvakoudis and others et all (2007) 
that the Basketball training program would help to develop the physical fitness for the game.

This is achieved the first assumption that the proposed training program lead to the development of some of the physical abilities for young basketball players.

Second: Discussion the result of Performance Skills tests:

Table (5) The Arithmetic Mean, the Standard Deviation, Percentage of improvement and T-test between the pre and in between performance skills in the main measurements for the research sample

\begin{tabular}{|c|c|c|c|c|c|c|c|c|}
\hline \multirow{2}{*}{\begin{tabular}{l|}
$\mathbf{N}$ \\
1
\end{tabular}} & \multirow{2}{*}{$\begin{array}{c}\text { Measurement } \\
\text { Passing (points) }\end{array}$} & \multicolumn{2}{|c|}{ Pre- Evaluate } & \multicolumn{2}{|c|}{ In between } & \multirow{2}{*}{$\begin{array}{c}\begin{array}{c}\text { Different } \\
\text { between } \\
\text { two mean }\end{array} \\
0 . \varepsilon .\end{array}$} & \multirow{2}{*}{$\begin{array}{l}\text { Percentage of } \\
\text { improvement } \\
1.01\end{array}$} & \multirow{2}{*}{$\frac{\mathrm{T}}{\text { Test }}$} \\
\hline & & $01 . \varepsilon \cdot \pm$ & A. IT & $07 . \wedge \cdot \quad \pm$ & $V .0 \leqslant$ & & & \\
\hline 2 & Dribbling ended shooting (sc) & $1 \cdot v$ & I. Y & $9.0 . \quad \pm$ & $\because V V$ & $\because v O_{-}$ & $0.7 \leq$ & *0.1 \\
\hline 3 & Dribbling (sc) & 9.7. & $1 . r \cdot$ & ^. vo & 1.7 & $\cdot \wedge \nearrow_{-}$ & $\wedge .9 r$ & $*\rceil . \vee$ \\
\hline 4 & Jump shot (points) & $\because$ Vo & $\because \vee 9$ & r. $\quad \pm$ & $\because \wedge$ & r.00 & re. & $* 11 . \leqslant r$ \\
\hline 5 & Lay up (points) & $\wedge .0$. & 7.91 & $19 . \ldots \pm$ & 0.01 & $1 \cdot 0$ & Ir.or & $* \vee . \vee T$ \\
\hline 6 & Rebounding (points) & 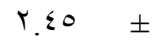 & 1.19 & $\varepsilon . v \cdot \quad \pm$ & $\because \wedge$ & r. ro & $91 . \wedge \varepsilon$ & $* 11.0$ \\
\hline
\end{tabular}

T-test $=2.93$ at 0.05

Table (6) The Arithmetic Mean, the Standard Deviation, Percentage of improvement and T-test between the pre and post evaluate the performance skills in the main measurements for the research sample

\begin{tabular}{|c|c|c|c|c|c|c|c|c|c|}
\hline \multirow{2}{*}{\begin{tabular}{l|}
$\mathbf{N}$ \\
1
\end{tabular}} & \multirow{2}{*}{$\begin{array}{c}\text { Measurement } \\
\text { Passing (points) }\end{array}$} & \multicolumn{3}{|c|}{ Pre- Evaluate } & \multicolumn{2}{|c|}{ In between } & \multirow{2}{*}{$\begin{array}{c}\begin{array}{c}\text { Different } \\
\text { between } \\
\text { two mean }\end{array} \\
1 \cdot .7 .\end{array}$} & \multirow{2}{*}{$\begin{array}{c}\begin{array}{l}\text { Percentage of } \\
\text { improvement }\end{array} \\
r \cdot . T r\end{array}$} & \multirow{2}{*}{$\begin{array}{c}\begin{array}{c}\mathrm{T} \\
\text { Test }\end{array} \\
* \mid r_{.} \varepsilon\end{array}$} \\
\hline & & $01 . \varepsilon$. & \pm & N.It & rr... $=$ & 0.04 & & & \\
\hline 2 & Dribbling ended shooting (sc) & $1 \cdot \because v$ & \pm & $1 . r T$ & ^. $\vee_{0}=$ & $.0 \mathrm{~V}$ & I.r. & 11.11 & $* \lambda .04$ \\
\hline 3 & Dribbling (sc) & 9.7. & \pm & $1 . r \cdot$ & V.qr $=$ &.$V \mu$ & $1.7 V_{-}$ & IV.rq & $* 1 . .97$ \\
\hline 4 & Jump shot (points) & $\because$ vo & \pm &. .19 & $0 .$. & $\cdot \wedge 7$ & $\varepsilon$ Y. & $077.7 \mathrm{~V}$ & $* 19.77$ \\
\hline 5 & Lay up (points) & 1.0 & \pm & 7.71 & ro.0. $=$ & 0.1. & IV... & $r \ldots$ & $* 11.0 \mathrm{~V}$ \\
\hline 6 & Rebounding (points) & $r_{.} \leqslant 0$ & \pm & 1.19 & $7 . \wedge$ & 1.10 & $\varepsilon . \mu_{0}$ & $1 V V .00$ & *YY.YT \\
\hline
\end{tabular}

T-test $=2.93$ at 0.05

Table (5) shows the differences of statistical measurement 0.05 between pre \&in between measurements tests for the benefit of in between measurement at rates ranging between $(1.05 \%$ : $340 \%$ ), is also apparent from table (6) the statistical differences at the level of 0.05 between pre \& post evaluate measurement in skill tests for the benefit of the post evaluate measurement at rates ranging between $(8.88 \%$ : $566.67 \%$ )

This difference is due to the improvement in all skill tests during the proposed training program, which is a mix of physical and skills preparation and give the player the ability to use the ball as much as he can, while in the classic program, the performance based on the warm-up and physical exercises without a ball, that may take the time of between 30:45 minutes and then held the ball for skills performance, But in the proposed training program by the performance of the exercises, which allows the player to held the ball since starting the warm-up till he finish all the exercise, which increases the sense the ball and leads to improve the performance of the skills, in addition to the fact that the program included training about control the ball skills and the feet movements and dribbling, passing and combined exercises in addition to minimatches.

The researcher refers that also due to the improvement of the basic skills performance to the development that have been taken place in the physical abilities (flexibility - speed explosive strength- coordination - agility), as the development of the physical abilities lead to the improvement of skills performance, This is 
agreed with what was reached by the study of Matavulj D et al and others (2001), Amr Hassan Tamman (2000), Mohamed Abdel-Rahim, Imad Al-Din Nofal (1993) and Mohamed AbdelWahab (1980) that the development of the physical fitness lead to the development of skills performance.

This is the result confirms the validity of the second assumption that the proposed training program lead to improve the level of skills performance for young basketball players.

\section{Conclusions:}

Within the results that could be reached from the data analysis will enable the researcher to do the following:

1. The proposed training program, which is a mix of physical and skills preparation led to the development of (speed - agility - explosive strength - Accuracy - flexibility- coordination) for young basketball players less than 12 years old.

2. The proposed training program, which is a mix of physical and skills preparation led to the improvement of (lay-up shot - jump shot rebounding - passing - dribbling) for young basketball players less than 12 years old.

\section{References:}

1- Afaf Abdul Karim (1993): Teaching methods in sports education, knowledge facility, 50 .

2- Ahmed Abdullah Roubi (1996): The impact of training exercises using weightlifting competition on skills performance for young basketball players less than 14 years, nonpublished master's research, Faculty of sports education, Port Said, Suez Canal University, 66.

3- Ali Fahmi Al Beik (1992): The foundations for the preparation of soccer players and games, $\mathrm{Al}$ Toni printing press, 28-32.

4- AmerSaadAmer (2008): The impact of proposed amendments in the Law of the Basketball for young people on the effectiveness of the offensive skills, nonpublished master's research, Faculty of physical education for Men, University of Alexandria, 66.
5- American Sport Education Program (2001): Coaching youth basketball third edition, human kinetics, 6 .

6- Amr Hassan Ali (2000): The impact of the training program using the bolometric on the development of muscles ability and jump shooting skills for Basketball, a master's research, Faculty of Sport Education, University of Tanta, 89.

7- Bastaweesy Ahmed (1996):

Fundamentals and theories of the Movement, the House of the Arab Thought, the first edition, 172,173 .

8- Efstratiosvamvakoudis, et all (2007) : The effects of basketball training on maximal oxygen uptake, muscle strength, and joint mobility in young basketball players, journal of strength and conditioning research, national strength \& conditioning association, 2007, 21(3), 930-936.

9- Federation international de basketball international basketball federation FIBA (2005) , Mini-Basketball rules.

10- Maríacañadas et al (2009) : The relationship between the pedagogical variables of coaching a mini-basketball team, revista de psicologíadeldeporte ,. vol. 18 - suppl., pp. 319323, issn: 1132-239.

11- Martin lee (1998): coaching children in mini-basketball fiba mini-basketball, roystonhertfordshire sg8 5nb united kingdom, 10,11 .

12- Matavulj d et al (2001) : The effects of plyometric training on jumping performance in junior basketball players, research center, faculty for physical culture , belgrade, yugoslavia, jun 188 .

13- Mohamed Abdel-Wahab (1980): The impact of training with heavy loads to develop the explosive strength on some of the physical fitness skills for young age basketball players, the scientific Conference for physical education studies and research, may.

14- Mohamed Abdul Rahim Ismail, Imad alDin Nofel (1993) : The explosive strength and its relationship with triple shotting in the Basketball, theories and applications, No. 14, Alexandria. 
15- Mohamed Mahmoud Abdel-Dayem, Mohamed SobhiHassanein (1999): The latest in Basketball, the scientific foundations and applied, the House of the Arab Thought, the second edition,133-142.

16- Mohamed SobhiHassanein (2004): The Measurement and Evaluation in physical education and sports, the House of the Arab Thought, the sixth edition,pp 79-90.

17- Omar Shaker Omar and Sanaa Abbas Ibrahim (1999): The amendment to the sizes of the basketball court for young age players ( mini basketball) in accordance with the rules of the Specialists in ergonomicsand human factors and its impact on the physiological performance for some of the body organs, theories and applications, No. 32 .
18- Piñar, $\mathrm{m}^{\mathrm{a}}$ isabel; et al (2009) : Participation of mini-basketball players during small-sided competitions , revista de psicologíadeldeporte, vol. 18, núm. 3,. 445-449.

19- Sanaa Abbas Ibrahim (2006): The development of skills performance used in the complex motor skills for young basketball players age (9-12) years, published theories and applications, the number of fifty-ninth, Faculty of physical education for Men, University of Alexandria, 65.

20- Shabaan Ibrahim Muhammad (2003) : The Basketball for young people, library of Faculty of Sports Education for Men, Abu Qir, 14. 